\title{
Stability of CT scan findings in schizophrenia: results of an 8 year follow-up study
}

\author{
BARBARA P ILLOWSKY, DENISE M JULIANO, LLEWELLYN B BIGELOW, \\ DANIEL R WEINBERGER
}

From the Clinical Brain Disorders Branch, Intramural Research Program, National Institute of Mental Health, Washington, DC, USA

SUMMARY Earlier cross-sectional studies have suggested that CT findings of ventricular enlargement and increased cortical markings in schizophrenic patients are not progressive, but individual patients have rarely been followed prospectively. Fifteen patients with chronic schizophrenia were rescanned on the same model machine after 7 to 9 years of continuous illness and, in seven cases, of continuous hospitalisation. It was not possible to demonstrate significant changes in either ventricular-brain ratio or frontal atrophy scores. These results suggest that the pathologic process responsible for CT changes in schizophrenia is static and is not affected by 8 years of neuroleptic medication and institutionalisation.

The presence of ventricular enlargement in some schizophrenic patients has led to speculation about the importance of structural brain pathology in the pathogenesis of the illness. ${ }^{12}$ This non-specific finding could arise from focal pathology of periventricular structures or could be part of a more generalised process as seen in a variety of neurological diseases. The time course of ventricular enlargement may provide insight into the nature of the underlying neuropathological process. Stable ventricular size would be expected with a static lesion, while progressive enlargement would suggest ongoing degeneration of cerebral structures and might implicate psychiatric treatment such as medication or institutionalisation as playing a causative role. ${ }^{3}$

Earlier studies have provided both indirect and direct evidence that lateral ventricular enlargement is not progressive. Repeated pneumoencephalographic studies failed to reveal an increase in lateral ventricular size in most schizophrenic patients 2 months to 8 years after the initial studies despite clinical deterioration in many. ${ }^{4}$ The majority of computed tomography (CT) studies of ventricular size have failed to

Address for reprint requests: Barbara P Illowsky, MD, National Institute of Mental Health, William A White Building, Saint Elizabeths Hospital, Washington, DC 20032, USA.

Received 18 March 1987 and in revised form 19 June 1987. Accepted 4 August 1987 show a correlation between age or duration of illness and ventricular enlargement. ${ }^{5-7}$ Other CT studies have shown that lateral ventricular enlargement is already present in some schizophreniform patients by the time of their initial admission. ${ }^{8-10}$

Nasrallah et al recently published a preliminary report in which patients were restudied 3 years after their initial scans. ${ }^{11}$ No consistent change in ventricular size was seen in these 11 patients as a group; while ventricular size increased slightly in four patients, it decreased in three. A methodological problem noted by the authors, however, is that a different CT scanner was used for the follow-up studies. The magnitude of the error that might arise when quantitatively comparing scans done on different machines is unclear, but may not be trivial.

We report a 7 to 9 year follow-up study of lateral ventricular size and frontal cortical markings in 15 patients with chronic schizophrenia, performed on the same model CT scanner. We found no evidence for progression of the CT findings.

\section{Subjects}

An attempt was made to contact all locally residing patients who had participated in an earlier study of ventricular size conducted in 1977-1979. ${ }^{5}$ Eighteen patients were available and consented to follow-up CT scans. The patients were selected without knowledge of their previous CT results, age, or duration or severity of illness. All patients met RDC criteria for schizophrenia at the time of the initial scan. ${ }^{12}$ 


\section{Methods}

CT scans were performed on an EMI 1010 head scanner at $15^{\circ}$ to the orbitomeatal line. Ten to 12 cuts were obtained in each patient and the slice showing maximum area of the lateral ventricles selected for measurement with a mechanical planimeter as previously described. ${ }^{5}$ Independent tracings were made in triplicate by two researchers; the reported ventricular brain ratio (VBR) is the mean of these values. Ventricles too small to be measured were assigned a VBR value of $0 \cdot 5$. Scans from 1977-1979 were remeasured for this study. Some of these initial scans were available only as Polaroid photographs so that the raters were not blind as to which were old and which were follow-up scans for all measurements. Raters were blind as to patient identity and previously determined VBRs.

Frontal atrophy was assessed by a visual scale with scores from $0-3$ assigned as previously described. ${ }^{13}$

The VBRs of the original and follow-up scans were compared with a paired $t$ test. Correlations were done with Pearson or Spearman correlation coefficients.

\section{Results}

Of 18 patients rescanned for this study, three had to be excluded from subsequent analysis. Even with sedation two patients were unable to hold still enough to obtain an image free of artifact. One patient was excluded because he had sustained several strokes in the interval between scans making it difficult to interpret VBR progression.

The final patient sample consisted of 13 men and two women. The mean age was $40 \pm 7.8$ years (range 27-52) with an average length of illness of $22.5 \pm 6.9$ years (range 8.5-34 years). At the time of follow-up nine patients were inpatients and six were living in the community. Seven patients had been hospitalised continuously during the interval between scans.

Remeasurement of the original scans in the 15 remaining patients yielded a VBR of $6.0 \pm 4.6$ (mean $\pm \mathrm{SD}$; range $0 \cdot 5-13 \cdot 0$ ). This is essentially the same as the values obtained at the time of the original measurement $(6 \cdot 6 \pm 5 \cdot 2$; intraclass correlation coefficient $=0.92, \mathrm{p}<0.0001)$.

At follow-up, the VBRs measured $5.8 \pm 4.8$ (range $0.5-15.0)$ which is not different from the initial VBR $(\mathrm{t}=-0.46, \mathrm{p}<0.7)$. The mean interval between scans was 8.2 \pm 0.7 years (range 7-9 years) (see fig 1). Fxcluding unmeasurable examinations from analysis also revealed no differences in VBR in the remaining scans $(\mathrm{t}=-0.45, \mathrm{p}<0.7)$.

Frontal atrophy scores showed no change. The initial ratings averaged $0.27 \pm 0.46$, while follow-up ratings had a mean of $0 \cdot 14 \pm 0.30$. The atrophy rating scores remained the same for 13 patients. In the remaining two patients frontal atrophy was less apparent at follow-up than on the initial scan.

The table shows patients' age, VBR measurement on the initial and follow-up scans, and the interval between the scans. There were no correlations between ventricular size or the CT interval change and age, length of illness, or duration of hospitalisation. Patients who had been continuously hospitalised showed no differences in interval change as compared with those not continuously hospitalised.

\section{Discussion}

We were thus unable to demonstrate progressive ventricular enlargement or cortical atrophy in a group of schizophrenic patients over an interval of 7 to 9 years. During this period the patients went from a mean age of $32(19-45)$ years to $40(27-52)$ years, a period of life during which ventricular size in normal individuals does not increase appreciably. ${ }^{14}$

Nasrallah et al noted that an increase in ventricular size over the 3 year period of their study was seen more frequently in the patients with smallest ventricles. ${ }^{11}$ Our population showed no such trend; the patients with small ventricles were no more likely to show progression than those with large ventricles.

Although using the same model scanner for the initial and follow-up studies avoids the issues involved in comparing scans from different machines, there are still problems in comparing films obtained at different times. It is difficult to position the patient in the scanner so that the same level and angle are achieved at each examination. Such differences in patient place-co ment can influence the appearance and measurement of ventricular size. We cannot dismiss the possibility

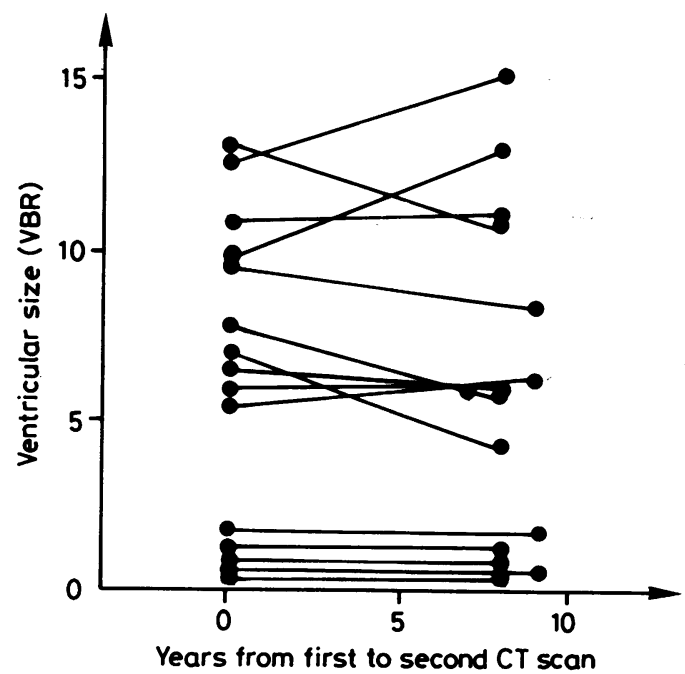

Fig 1 Change in ventricular size over the interval hetween initial and follow-up scans. 

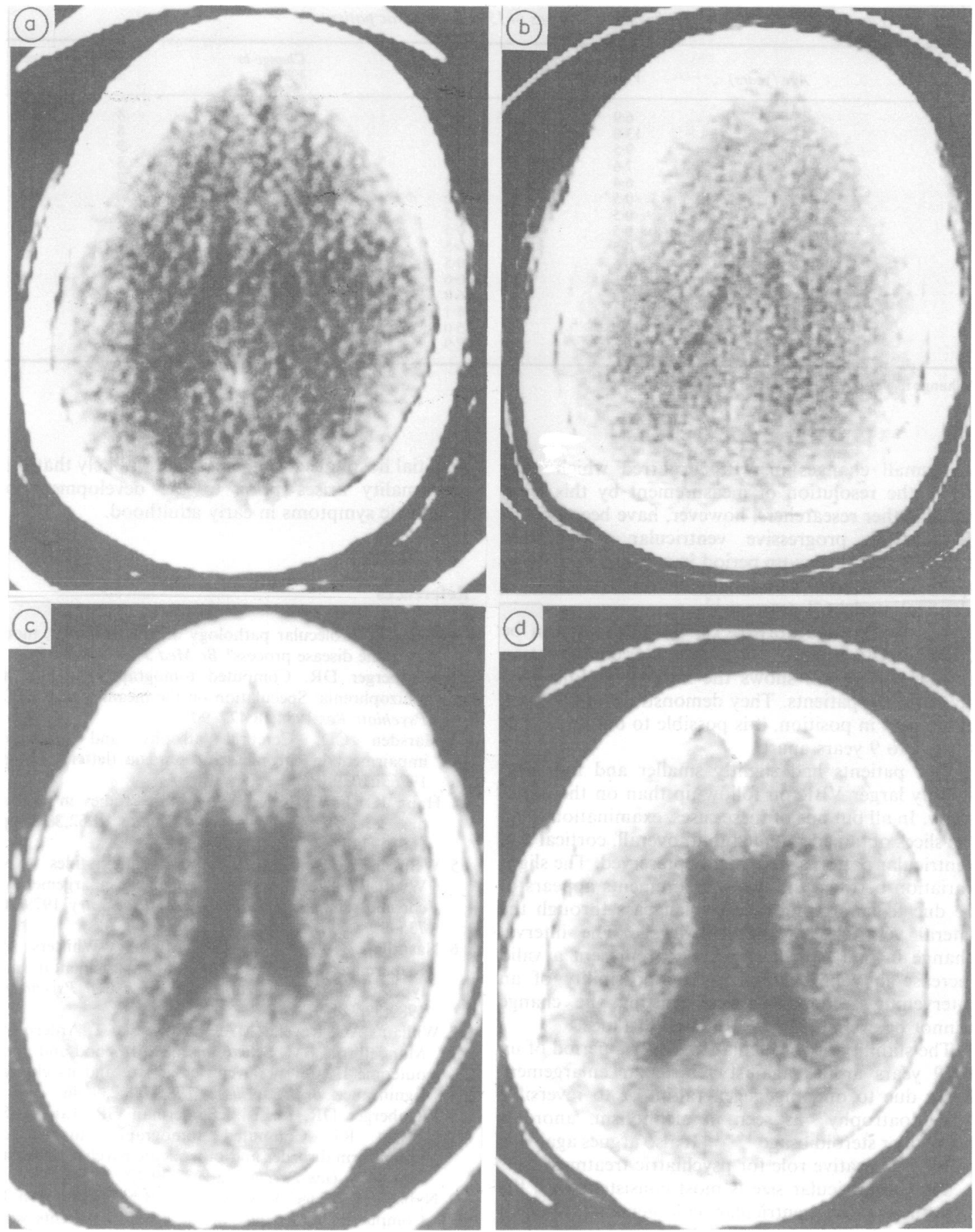

Fig 2 Initial and follow'-up CT scans obtained in two patients: (a) scan of a 28 year old schizophrenic obtained in 1977. (b) scan of same patient as (a), obtained in 1986 after 9 years of continuous inpatient treatment. (c) scan of a 29 year old man obtained in 1978. (d) scan of same patient as (c) obtained in 1986 after 8 years of continuous inpatient treatment. 
Table Initial and follow-up ventricular-brain ratio values in 15 schizophrenic patients

\begin{tabular}{|c|c|c|c|c|c|}
\hline No & Age (years) & $\begin{array}{l}\text { Initial } \\
V B R\end{array}$ & $\begin{array}{l}\text { Follow-up } \\
\text { VBR }\end{array}$ & $\begin{array}{l}\text { Change in } \\
V B R^{*}\end{array}$ & $\begin{array}{l}\text { Interval between } \\
\text { scans (years) }\end{array}$ \\
\hline $\begin{array}{r}1 \\
2 \\
3 \\
4 \\
5 \\
6 \\
7 \\
8 \\
9 \\
10 \\
11 \\
12 \\
13 \\
14 \\
15\end{array}$ & $\begin{array}{l}45 \\
43 \\
30 \\
48 \\
35 \\
45 \\
37 \\
27 \\
52 \\
41 \\
47 \\
38 \\
30 \\
51 \\
37\end{array}$ & $\begin{array}{r}6.9 \\
13.0 \\
9.5 \\
7.6 \\
6.4 \\
0.5 \\
0.5 \\
0.5 \\
0.5 \\
0.5 \\
10.6 \\
5.8 \\
5.2 \\
12.5 \\
9.6\end{array}$ & $\begin{array}{r}4.2 \\
10.3 \\
7.5 \\
5.7 \\
5.8 \\
0.5 \\
0.5 \\
0.5 \\
0.5 \\
0.5 \\
10.6 \\
6.0 \\
6.1 \\
15.0 \\
12.9\end{array}$ & $\begin{array}{c}-2.7 \\
-2.7 \\
-2.0 \\
-1.9 \\
-0.6 \\
0 \\
0 \\
0 \\
0 \\
0 \\
0 \\
0.2 \\
0.9 \\
2.5 \\
3.3\end{array}$ & $\begin{array}{l}8 \\
8 \\
9 \\
8 \\
7 \\
8 \\
9 \\
8 \\
7 \\
9 \\
7 \\
8 \\
9 \\
8 \\
8\end{array}$ \\
\hline
\end{tabular}

${ }^{*}$ Change in VBR $=$ follow-up VBR-initial VBR.

that small changes in VBR occurred which were below the resolution of measurement by this technique. Other researchers, however, have been able to demonstrate progressive ventricular enlargement after a 2 year follow-up period in a group of patients with senile dementia using similar techniques and an identical model CT scanner. ${ }^{15}$

Even with these drawbacks, the CT scan can be quite consistent in revealing ventricular configuration and size. Figure 2 shows the initial and follow-up scans in two patients. They demonstrate that despite differences in position, it is possible to obtain similar scans 7 to 9 years apart.

Five patients had slightly smaller and four had slightly larger VBR on follow-up than on the initial study. In all but one of these cases, examination of all the slices obtained revealed that, overall, cortical and ventricular patterns were highly preserved. The slight variation between the two measurements appears to be due to comparing slices which pass through the lateral ventricles at different levels. The interval change in one patient appears to represent a valid increase in ventricular size. The possibility of an intervening secondary illness causing the change cannot be excluded in this isolated instance.

The stability of ventricular size over a period of up to 9 years argues against ventricular enlargement being due to ongoing degeneration or to reversible "pseudoatrophy" as seen in alcoholism, anorexia nervosa or steroid usage. ${ }^{16-18}$ It also argues against a primary causative role for psychiatric treatment. ${ }^{3}$

Stable ventricular size is most consistent with the hypothesis that ventricular enlargement, when it occurs, is due to an early developmental lesion or to past and arrested degeneration of cerebral structures. ${ }^{19}$ These results, along with studies showing that ventricular enlargement is already present at the time of initial hospitalisation, ${ }^{8-10}$ makes it likely that this abnormality arises prior to the development of diagnostic symptoms in early adulthood.

\section{References}

1 Crow TJ. Molecular pathology of schizophrenia: more than one disease process? Br Med $J$ 1980;28:66-8.

2 Weinberger DR. Computed tomography findings in schizophrenia: Speculation on the meaning of it all. $J$ Psychiatr Res 1984;18:477-90.

3 Marsden CD. Cerebral atrophy and cognitive impairment in chronic schizophrenia (letter). Lancet? 1976;ii: 1079.

4 Haug JO. Pneumoencephalographic studies in mental disease. Acta Psychiatr Scand 1962;38(Suppl 165): $1-114$.

5 Weinberger DR, Torrey EF, Neophytides AN, Wyatt RJ. Lateral cerebral ventricular enlargement in chronic schizophrenia. Arch Gen Psychiatry 1979;36: 735-9.

6 Nasrallah HA, Jacoby CG, McCalley-Whitters M, Kuperman S. Cerebral ventricular enlargement in subtypes of chronic schizophrenia. Arch Gen Psychiatry 1982;39:774-7.

7 Williams AO, Reveley MA, Kolakowska T, Ardern M, Mandelbrote BM. Schizophrenia with good and poor outcome II: Cerebral ventricular size and its clinical significance. Br J Psychiatry 1985;146:239-46.

8 Weinberger DR, DeLisi LE, Perman GP, Targum S, Wyatt RJ. Computed tomography in schizophreniform disorder and other acute psychiatric disorders. Arch Gen Psychiatry 1982;39:778-83.

9 Nyback H, Wiegel F-A, Berggren B-M, Hindmarsh T. Computed tomography of the brain in patients with acute psychosis and in healthy controls. Acta Psychiatr Scand 1982;65:403-14.

10 Schultz SC, Koller MM, Kishore PR, Hamer RM, Gehl JJ, Friedel RO. Ventricular enlargement in teen- 
age patients with schizophrenia spectrum disorder. Am J Psychiatry 1983;140:1592-5.

11 Nasrallah HA, Olson SC, McCalley-Whitters M, Chapman S, Jacoby CG. Cerebral ventricular enlargement in schizophrenia: A preliminary follow-up study. Arch Gen Psychiatry 1986;43:157-9.

12 Spitzer RL, Endicott J, Robins E. Research Diagnostic Criteria (RDC) for a Selected Group of Functional Disorders, ed 3. New York: Biometrics Research, 1977.

13 Shelton RC, Doran A, Pickar D, Weinberger DR. Cerebral structural pathology in schizophrenia: evidence for a selective prefronted cortical defect. $\mathrm{Am} \mathrm{J}$ Psychiatry (in press).

14 Barron SA, Jacobs L, Kinkel WR. Changes in size of normal lateral ventricles during aging determined by computerized tomography. Neurology 1976;26:1011-3.

15 Naguib M, Levy R. CT scanning in senile dementia. A follow-up of survivors. $\mathrm{Br} \quad J \quad$ Psychiatry 1982;141:618-20.

16 Cola LA, Mastaglia FL. Computerized tomography in chronic alcoholics. Alcohol Clin Exp Res 1981;5:283-94.

17 Deonna T, Voumard C. Reversible cerebral atrophy and corticotrophin. Lancet 1979;ii:207.

18 Heinz ER, Martinez J, Haenggeli A. Reversibility of cerebral atrophy in anorexia nervosa and Cushing's syndrome. J Comput Assist Tomogr 1977;1:415-8.

19 Weinberger DR. Implications of normal brain development for the pathogenesis of schizophrenia. Arch Gen Psychiatry 1987;44:660-9. 